\title{
Determination of glassfibre-reinforced cement durability
}

\author{
K KOMLOS, B BABÁL, M VANIŠ* and J KOZÁNKOVÁ* \\ Slovak Academy of Sciences, Dúbravská 9, 84220 Bratislava, Slovak Republic \\ *Slovak Technical University, Radlinského 9, 81237 Bratislava, Slovak Republic \\ MS received 26 October 1993
}

\begin{abstract}
Atstract. This paper deals with accelerated and long-term durability tests of glassfibrereinforced cement composites. AR glassíibres REZAL, ESAP and SVUS 16, developed in Czechoslovakia, and Cem-FIL 1 fibres developed in the United Kingdom were applied. REZAL and ESAP fibres are of a low zirconium dioxide content, SVUS 16 and Cem-FIL 1 fibres are of a high zirconium dioxide content. The accelerated and the long-term ageing process were studied. The modulus of rupture was determined after $28,90,180,360,720$ and 1080 days, and 6 years of ageing. The investigated glassfibre types have shown a high alkali resistance, mostly when dry curing was applied. Within the testing period of six years, glassfibres of low as well as high zirconium dioxide content show similar behaviour in the cement matrix.
\end{abstract}

Keywords. Cement composites; glassfibres; alkali resistance; ageing process; interfacial bond; durability.

\section{Introduction}

The function of fibres in the relatively brittle cement matrix is to delay and control the tensile cracking of the material so that an unstable and uncontrolled tensile crack growth is transformed into a slow, controlled crack growth. It is this unique characteristic of fibre reinforcement that gives the composite properties of post-cracking tensile resistance, increased tensile strain capability and enhanced energy absorption.

Glassfibre-reinforced cement (GRC) came into existence as a practical construction material about 20 years ago with the commercial introduction of alkali-resistant glassfibres based on high-zirconia glass compositions (Majumdar and Ryder 1968). In the recent years a larger number of alkali-resistant glass compositions were developed worldwide. These compositions contain also other oxides responsible for alkali resistance, e.g. $\mathrm{TiO}_{2}, \mathrm{BaO}$ (see table 1) and $\mathrm{ZnO}$. However, $\mathrm{ZrO}_{2}$ remains the most important component in the majority of alkali-resistant glass compositions.

All ccmmercial glassfibre compositions are based on silicate glasses; these are, almost inevitably, subject to some interactions with a strongly alkaline environment, such as that which exists in Portland cement. This problem is being solved either by applying alkali-resistant glassfibre provided with effective coating materials, or by decreasing the alkalinity of the cement matrix. This can be done either with the help of different pozzolans or by using silica-fume. At the most fundamental and microscale level it has been important to understand the extent of such reactions, their effects on fibre strength, and the relationship between fibre strength changes and composite behaviour (Oakley 1981; Proctor 1982).

In attempting to provide the necessary information on expected long-term behaviour over many years, it became clear that simple extrapolation of results from weathering exposure programmes was not sufficient to support the rapid development of use in different climates (Hannant 1978; Komloš et al 1991) 
Table 1. Glassfibre chemical composition.

\begin{tabular}{|c|c|c|c|c|c|c|c|c|}
\hline \multirow[b]{2}{*}{ Fibre } & \multicolumn{8}{|c|}{ Components (weight \%) } \\
\hline & $\mathrm{SiO}_{2}$ & $\mathrm{ZrO}_{2}$ & $\mathrm{BaO}$ & $\mathrm{Na}_{2} \mathrm{O}$ & $\mathrm{Al}_{2} \mathrm{O}_{3}$ & $\mathrm{CaO}$ & $\mathrm{Fe}_{2} \mathrm{O}_{3}$ & $\mathrm{TiO}_{2}$ \\
\hline REZAL & 59.29 & 4.97 & 9.94 & $10 \cdot 4$ & $5 \cdot 1$ & $10 \cdot 3$ & - & - \\
\hline ESAP & $65 \cdot 70$ & 4.95 & 6.80 & 10.5 & $4 \cdot 6$ & $7 \cdot 3$ & 0.15 & - \\
\hline SVUS 16 & $58 \cdot 30$ & $11 \cdot 40$ & - & $14 \cdot 3$ & - & $8 \cdot 6$ & - & 7.4 \\
\hline Cem-FIL 1 & 62.00 & $16 \cdot 70$ & - & 14.8 & 0.8 & $5 \cdot 6$ & - & 0.1 \\
\hline
\end{tabular}

\section{Accelerated testing methods}

Direct knowledge of the strength of the fibre reinforcement is an important factor in understanding the behaviour of any composite material, although the strength of the composite may in fact be influenced by a number of factors, including the strength of the matrix and the matrix/fibre interfacial bond, in addition to the fibre strength.

In the case of glassfibre-reinforced cements and mortars, the strength behaviour of the cements or mortar matrix was reasonably well understood and was predictable over a period of years. The strength of the fibre/matrix bonds was less well known, but it was the strength behaviour of the $A$ R glassfibre itself which was least understood-it had even been suggested (Litherland 1981; Oakley 1981; Proctor 1982) that the strength of the composite was not directly controlled by the strength of the fibres.

For the SIC (strand in cement) test a small block of cement paste or cement/sand mortar is cast around part of a typical, commercial, multifilament strand (see figure 1). The strand outside the cement is strengthened and protected by impregnation with resin and this is continued for a short distance into the cement to prevent damage and flexing at the edge of the block (Litherland 1981).

After casting the cement is allowed to set and cure for $24 \mathrm{~h}$ at $100 \% \mathrm{RH}$ and room temperature. Specimens are then transferred to a suitable storage environment for the required period, removed, and tested in direct tension. The tensile strength of the strand is then calculated from the breaking load, measured strand tex and fibre density.

The second accelerated test is performed as follows (Komloš et al 1989). The glassfibre-reinforced cement paste is compacted into a mould $40 \mathrm{~mm} \times 40 \mathrm{~mm} \times 160 \mathrm{~mm}$. After casting, the specimen is allowed to set and cure for $24 \mathrm{~h}$ at $100 \% \mathrm{RH}$ and room temperature. Specimens are then demoulded and transferred to a storage environment of $80^{\circ} \mathrm{C}$ and $100 \% \mathrm{RH}$ for the required period. The specimens are tested in flexure, third point loading being used. The strength ratio, GRC flexural strength to plain matrix flexural strength, is then calculated.

\subsection{Accelerated ageing procedure}

Extensive studies over the last several years (Proctor 1982, 1990; Knězek 1987; Komloš et al 1990) have shown that strength changes which occur in accelerated tests may be related directly to the weathering behaviour of real composites in different climates. For instance immersing SIC specimens containing Cem-FIL 1 fibres in water 
at $80^{\circ} \mathrm{C}$ for 4 days, or $50^{\circ} \mathrm{C}$ for 3 months, induces strength changes equivalent to exposure for around 20 years in British weather conditions (Proctor 1982), or for around 30 years in Czechoslovak weather conditions (Knězek 1987).

The above data are results of laboratory and weathering comparisons. However, a number of buildings existing for about 20 years, e.g. the building of Credit Lyonnaise Bank in London or the exhibition building in Stuttgart, Germany, can be regarded, to a certain degree, as proof of the validity of the above assumptions.

The accelerated ageing results from composites (Litherland 1981) stored in water at $50^{\circ} \mathrm{C}, 60^{\circ} \mathrm{C}$ and $80^{\circ} \mathrm{C}$ show a constant pattern of an initial falling-strength region (where the composite strength is directly proportional to fibre SIC strength) followed by a stable-strength region which appears to be maintained indefinitely. The weathering results extending over 10 years in the UK and for 2 to 5 years in other climates show a parallel fall in strength, with no sudden or unexpected changes due to the natural variation in humidity, temperature, etc. which occurs in real climates.

Investigations carried out recently have shown that the SIC ageing process can be divided into four phases. In the first phase no pronounced strength changes can be observed. In the second phase the hydration products destroy the strand coating The third phase is characterized by the abrasion of fibres by calcium hydroxide crystals, causing a steady strength retention. In the fourth phase the strand loses its strength. The above four phases can be compressed into two, where $A$ is the period of apparent alkali resistance, and $B_{k}$ the period of gradual strength retention. The time $A V_{k}$ taken for SIC strength to fall to a given value $k$ may be taken as a measure of the strength controlling cement/glass reaction

$$
A V_{k}=A-B_{k} \text {. }
$$

In order to eliminate factors influencing the manufacture of SIC specimens, the strength ratio was introduced

$$
P_{t}=\sigma_{1} / \sigma_{0} 100 \%
$$

where $\sigma_{0}$ is the initial strength of the glass strand $(24 \mathrm{~h}$ after the manufacture of the SIC specimen), and $\sigma_{1}$ the strength of the glass strand after time $t$ in water at a given temperature.

For Cem-FIL 1 fibres a simple $P_{t}=f(t)$ relationship was found. Curing temperature $50^{\circ} \mathrm{C}$ :

$$
\log P_{1}=2 \cdot 116005-0.278814 \log t,
$$

curing temperature $80^{\circ} \mathrm{C}$ :

$$
\log P_{\mathrm{t}}=1.828784-0.34804 \log t,
$$

where $P_{1}$ is the SIC strength ratio and $t$ the curing time of SIC specimens.

The investigations were carried out according to the procedures described before. Two types of AR glass fibres, REZAL and ESAP (see table 1), were used.

OPC 400 was used throughout the experiment. SIC specimens cured at $50^{\circ} \mathrm{C}$ were tested after 7, 14, 28, 90, 112 and 196 days of ageing. Specimens cured at $80^{\circ} \mathrm{C}$ were tested after 1, 3, 5, 7, 14 and 21 days. The test results are summarized in figures 2 and 3. Beam specimens $40 \mathrm{~mm} \times 40 \mathrm{~mm} \times 160 \mathrm{~mm}$, reinforced with all four fibre types (see table 1) and cured at $80^{\circ} \mathrm{C}$, were tested in flexure after $1,3,5,7,14$ and 21 days. The test results are given in figure 4. 


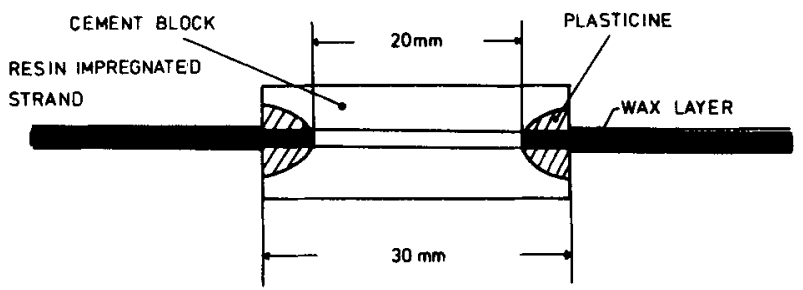

Figure 1. Strand-in-cement (SIC) specimen.

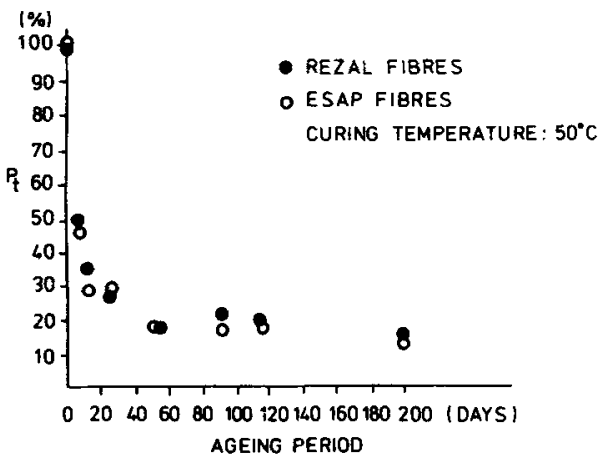

Figure 2. $P_{t}$ versus ageing period relationship (curing temperature $50^{\circ} \mathrm{C}$ ).

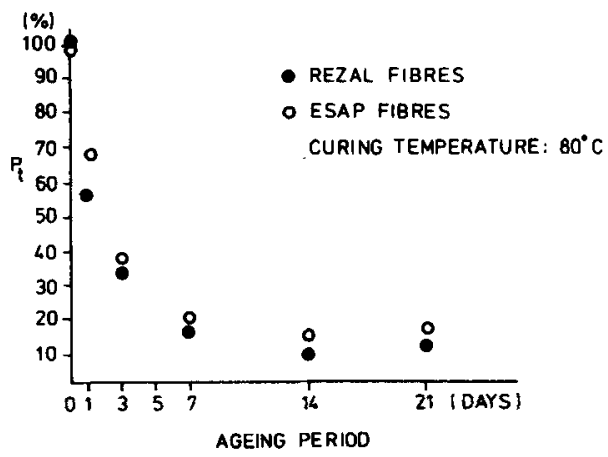

Figure 3. $P_{t}$ versus ageing period relationship (curing temperature $80^{\circ} \mathrm{C}$ ).

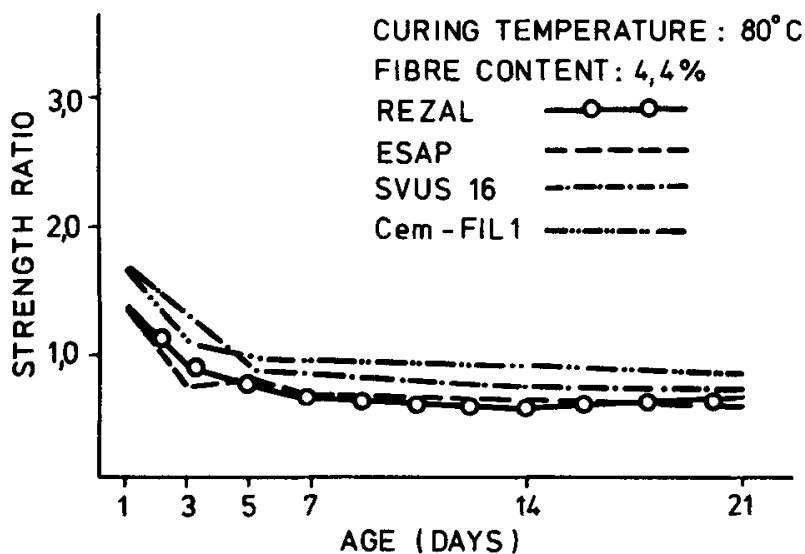

Figure 4. Strength ratio versus composite age relationship (curing temperature $80^{\circ} \mathrm{C}$ ). 


\section{Long-term testing methods}

\subsection{Materials and mixes}

A Portland cement type 400 was used to manufacture the cement paste. As fibre reinforcement REZAL, ESAP, SVUS 16, and Cem-FIL 1 alkali-resistant glassfibres were applied. Their chemical composition is given in table 1 . The fibre length was $36 \mathrm{~mm}$. The water/cement ratio of the cement paste was 0.37 . The following fibre weight fractions of glassfibres were incorporated into the cement paste: $0.4,1 \cdot 0,1 \cdot 6$, $2 \cdot 2,3 \cdot 3$, and $4 \cdot 4 \%$. The batches were mixed in a laboratory pan mixer, and the fibres were incorporated into the cement paste in such a way as to ensure a uniform and random distribution in the cement matrix.

\subsection{Casting, curing and testing}

The mixes were compacted in steel moulds on a vibrating table $(50 \mathrm{~Hz} ; 0.35 \mathrm{~mm})$. Three specimens $40 \mathrm{~mm} \times 40 \mathrm{~mm} \times 160 \mathrm{~mm}$ could be manufactured simultaneously in these moulds. Together with the fibre-reinforced specimens, plain specimens were cast. For each investigated parameter six specimens were manufactured. The obtained values are the mean strength values determined on these specimens.

After casting the specimens were cured in moulds for $48 \mathrm{~h}$ in a moist room $\left(20^{\circ} \mathrm{C}\right.$, $90 \% \mathrm{RH}$ ), and after the moulds were removed, one half of the specimens were stored in dry environment $\left(20^{\circ} \mathrm{C}, 60 \% \mathrm{RH}\right)$, and the second half in water $\left(20^{\circ} \mathrm{C}\right)$. The specimens were tested after $28,90,180,360,720$ and 1080 days, and 6 years of ageing. The specimens were tested in flexure, three point loading being used. Except beam specimens, also plate specimens $450 \mathrm{~mm} \times 120 \mathrm{~mm} \times 12 \mathrm{~mm}$ (see figure 5) were tested after 6 years of ageing. During this period they were placed at weathering exposure.

\subsection{Results}

For determination of the durability of GRC composites simple methods were applied. One of the introduced methods is based on the estimation of the retention of the strength ratio, i.e. the ratio of the flexural strength of fibre-reinforced specimens to the flexural strength of the plain cement matrix.

The results of investigations carried out with composites with a fibre content of $4.4 \%$ are summarized in figures 6 and 7 . In these figures the relation between the flexural strength ratio and the age of the tested specimen is plotted. The investigations carried out have shown that the specimens stored in water exhibit lower strength than dry-cured specimens. This is in good agreement with results published by other authors, as well as with our results obtained earlier (Komloš et al 1991).

After the strength tests were carried out, samples were taken for investigation under the SEM. According to these investigations, we may say that the fibre shape remained unchanged, even in the case of water curing, and that the fibre surface is covered with smaller and larger particles of hydration products. Only in some cases, we observed a partly damaged coating layer (see figures 8 to 19 ). 


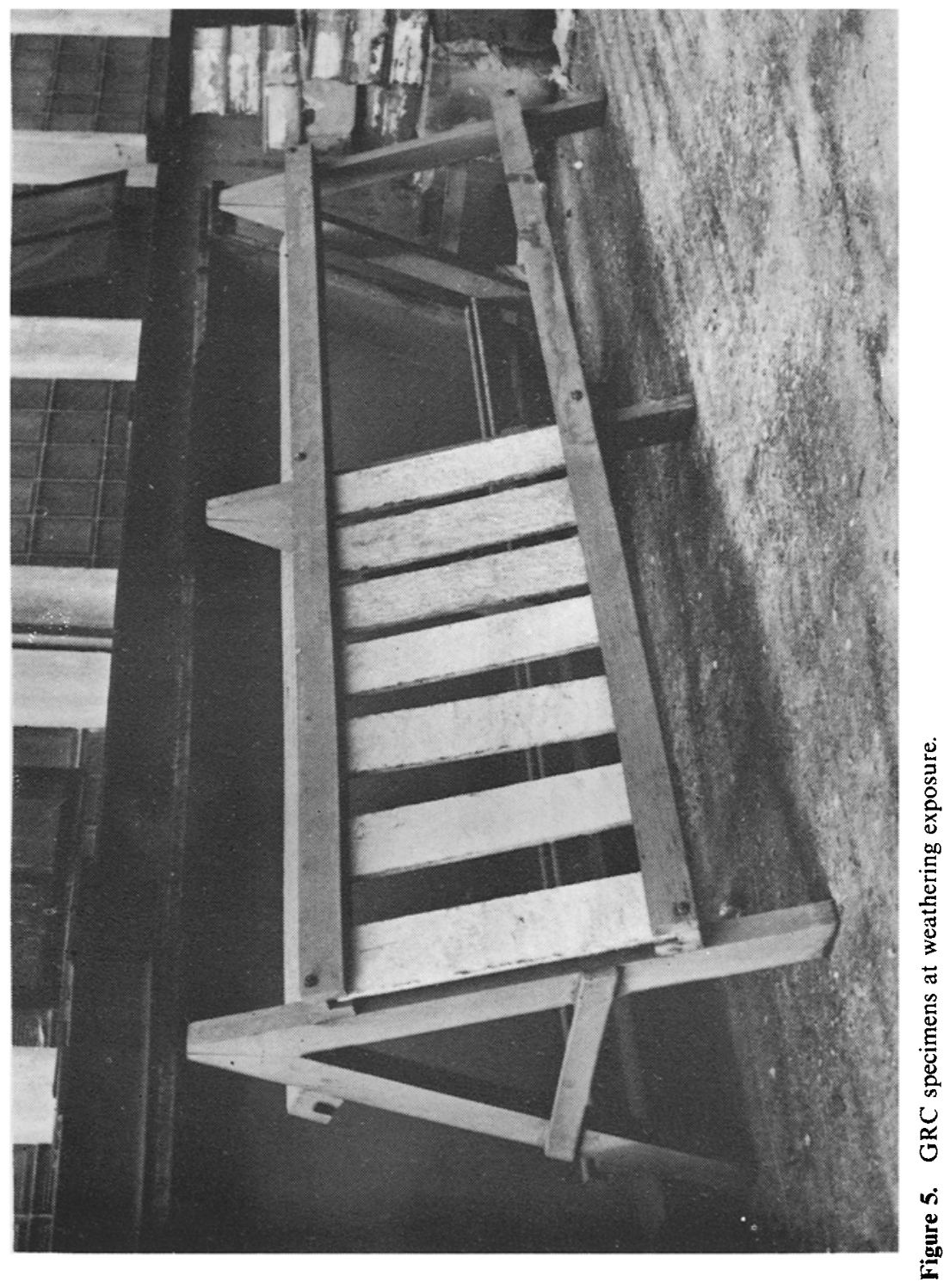




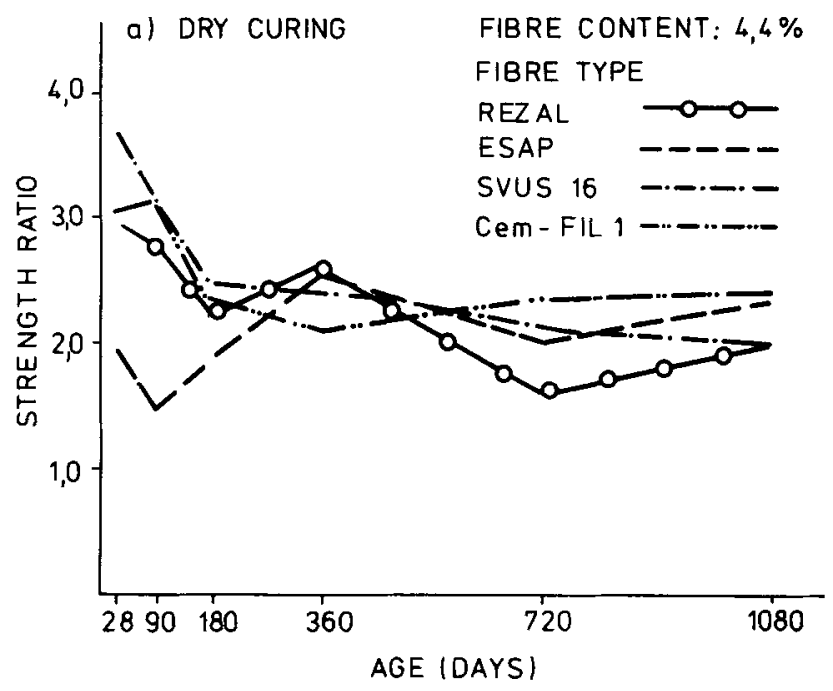

Figure 6. Strength ratio versus composite age relationship (dry curing).

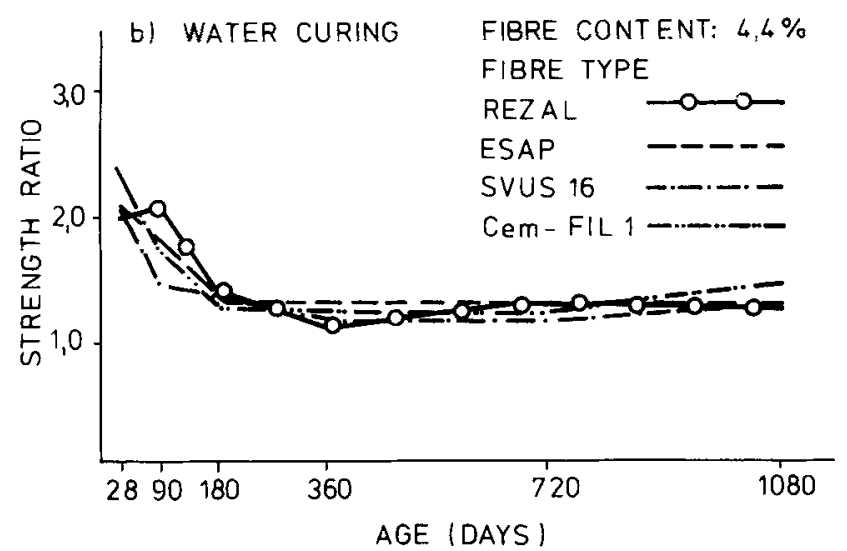

Figure 7. Strength ratio versus composite age relationship (water curing). 

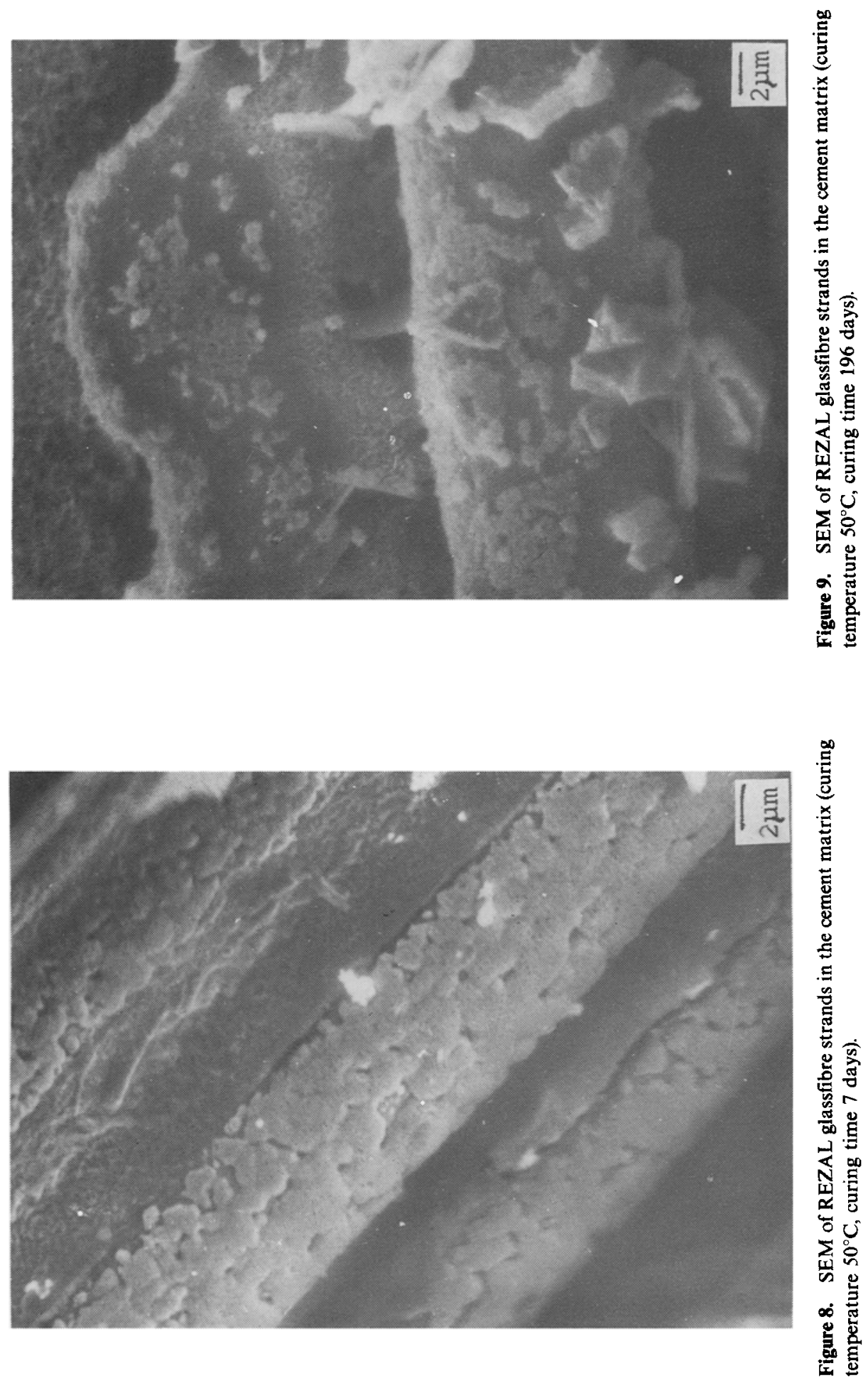

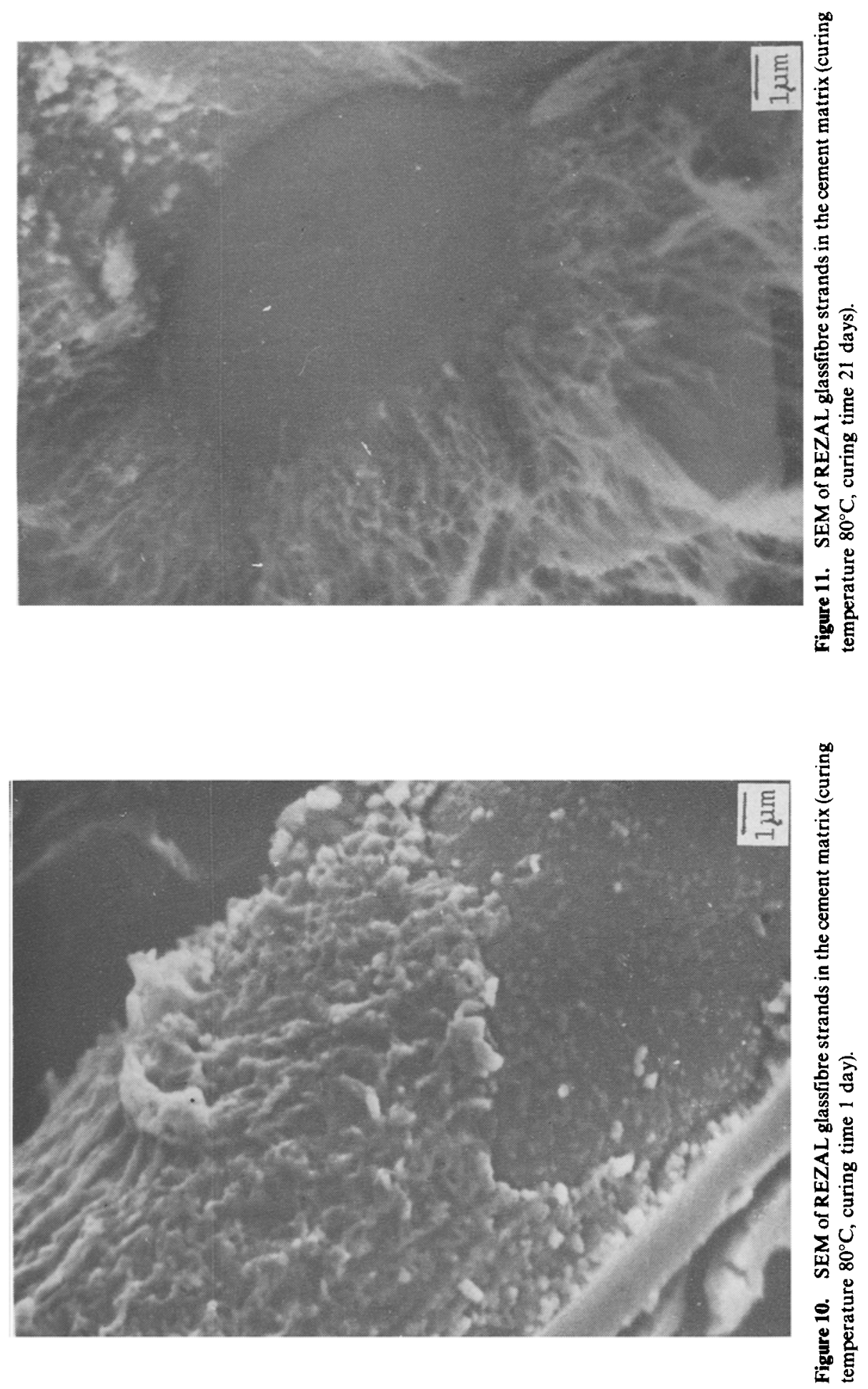

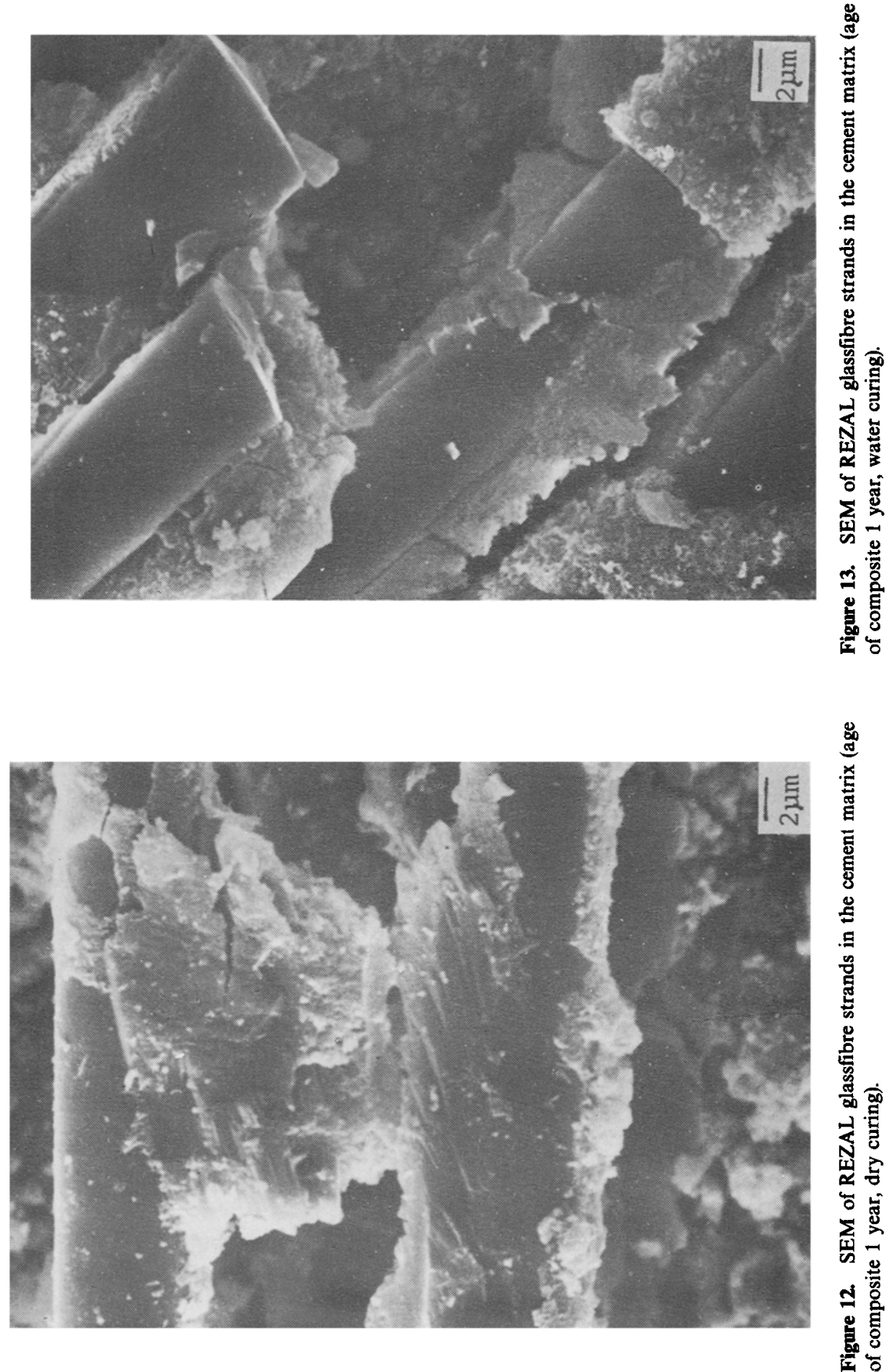

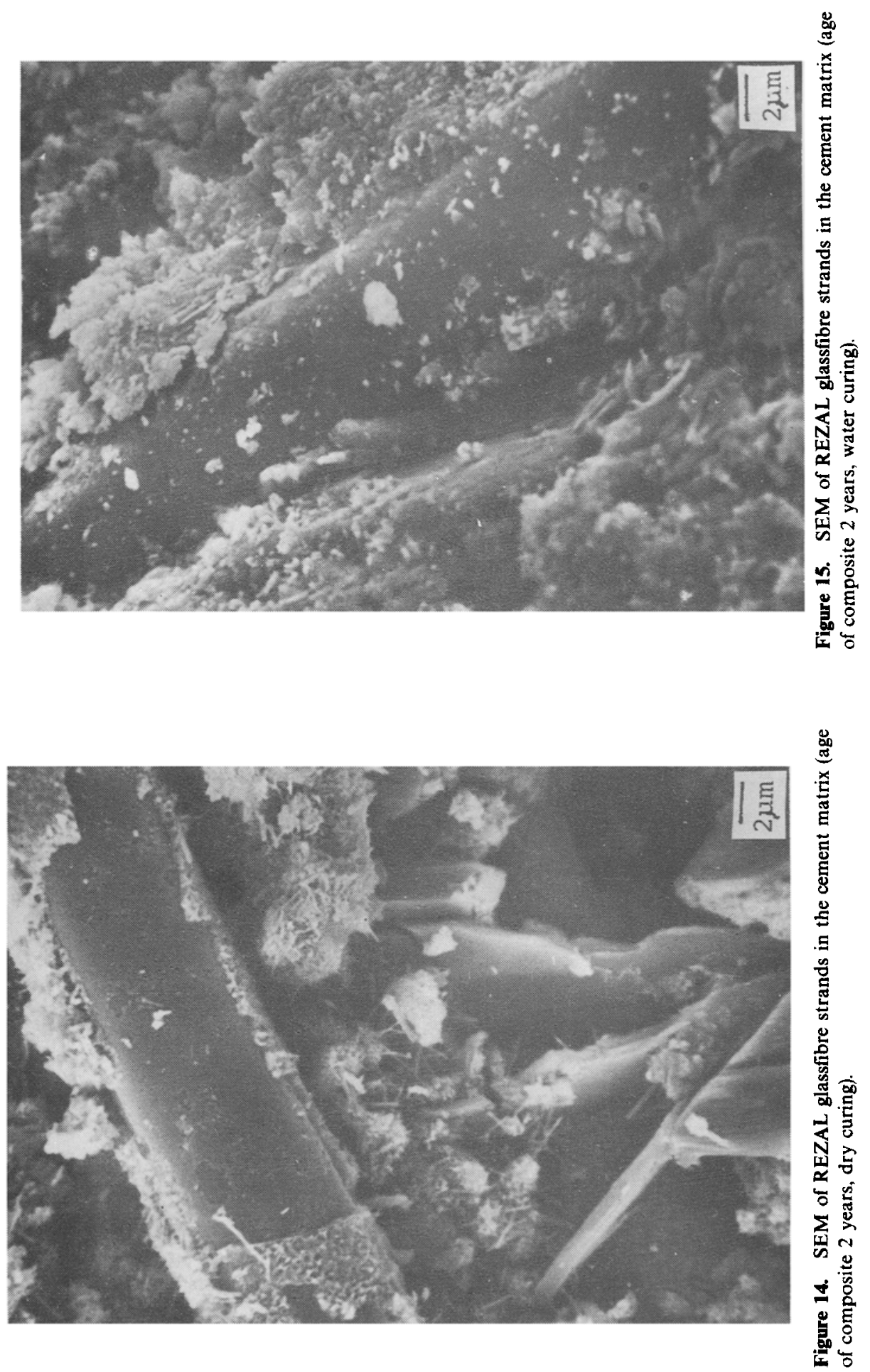

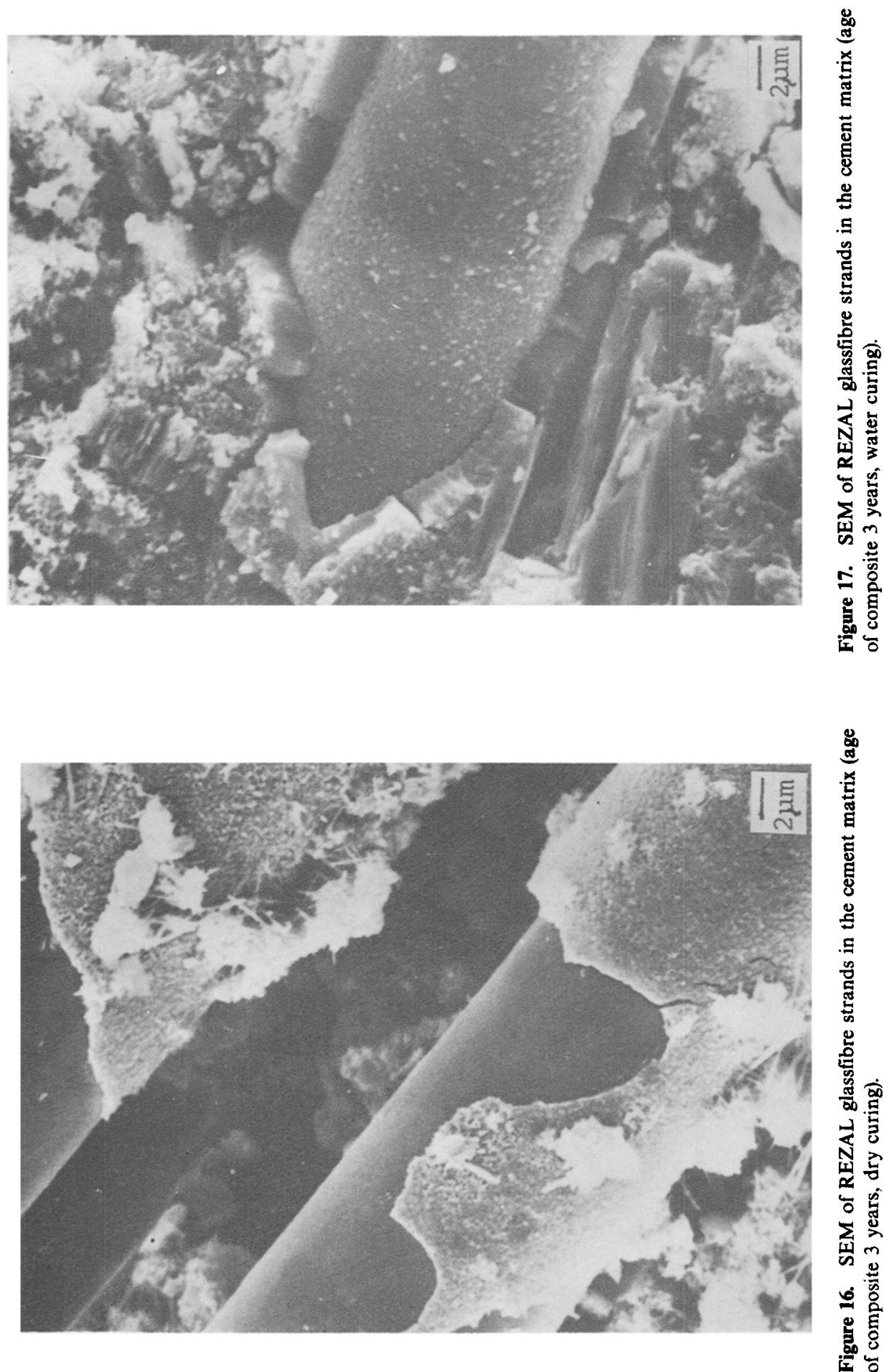

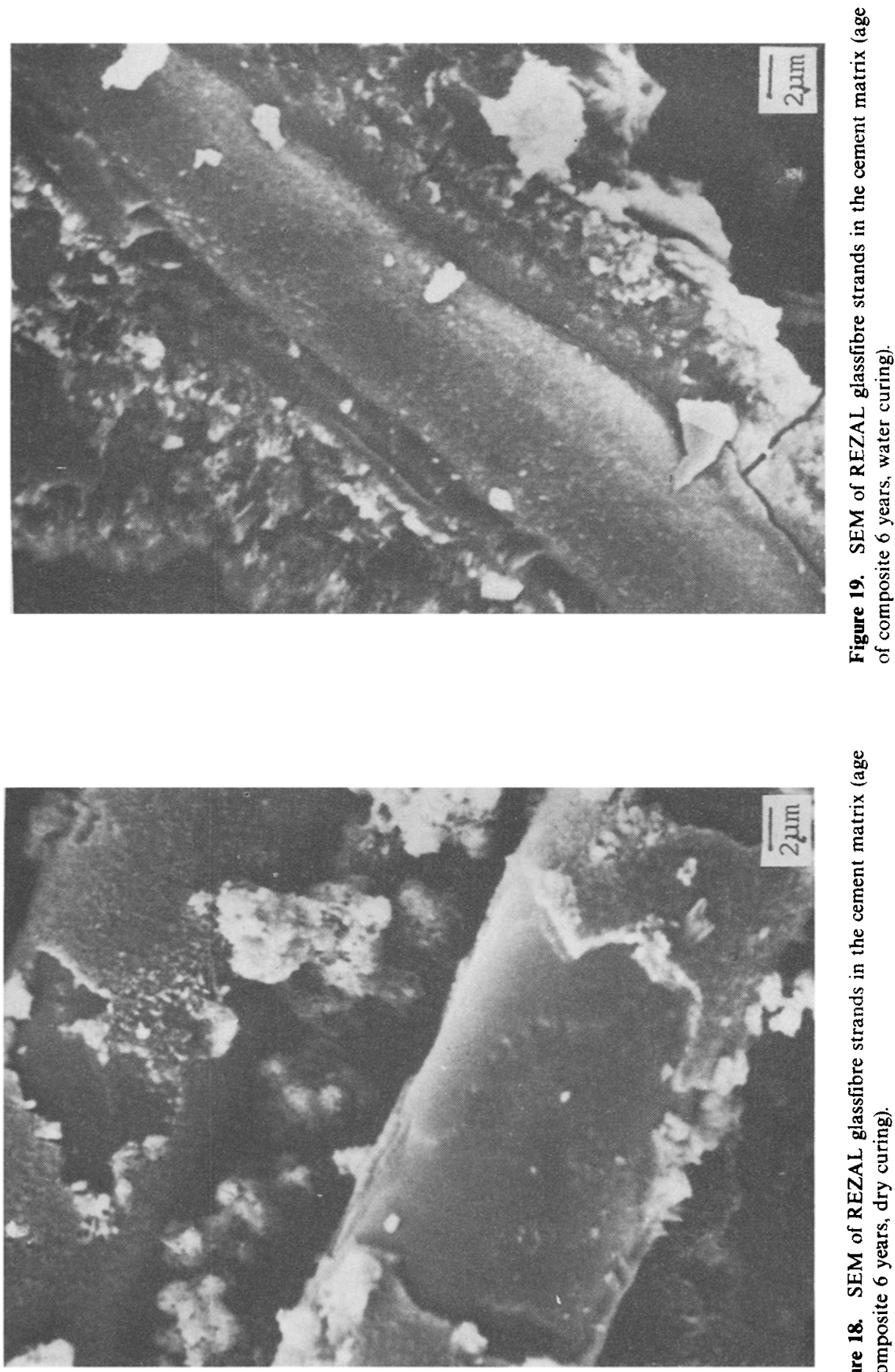

离

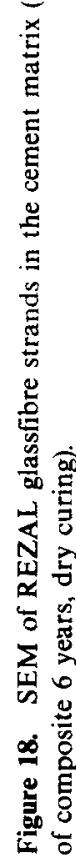




\section{Conclusions}

The applied test procedures have proved to be valuable and flexible experimental tools that enable comparisons to be made between glassfibre strength retention and glassfibre type. Changes in the strength of glassfibre strands in Portland cement have been accelerated by ageing in hot water at two temperatures, and the temperature dependence determined.

Water storage has proved to be more corrosive than dry curing. This has been shown by others previously.

The investigations have shown that even low-zirconium glassfibres show a relatively high alkali resistance. This fact enables their application in different structural elements.

\section{Acknowledgement}

The authors are grateful to the Slovak Grant Agency for science (grant No. 999 209/92) for partial support of this work.

\section{References}

Hannant D J 1978 Fibre cements and fibre concretes (Chichester, UK: Wiley Interscience)

Knězek J 1987 Stavivo 65412

Komloš K, Babál B, Vaniš M and Kozánková J 1989 Tiefbau 31150

Komloš K, Vaniš M, Kozánková J and Baúál B 1990 Mater. Eng. 1813

Komloš K, Babál B, Vaniš M and Kozánková J 1991 Tiefbau 33108

Litherland K L 1981 Cem. Concr. Res. 11455

Majumdar A J and Ryder J F 1968 Glass Technol. 978

Oakley D R 1981 The development of a method of predicting the weathering behaviour of glass reinforced cement composites, Proc. 2nd inter. conference on durability of building materials and components (Gaithersburg: National Bureau of Standards) p. 225

Proctor B A 1982 Composites 13173

Proctor B A 1990 Cem. Concr. Compos. 1253 